\title{
PENGARUH TERAPI AKUPUNKTUR PADA TITIK BL 13, LI 11, SP10, ST36 DAN HT7 TERHADAP PERBAIKAN IG.E PASIEN PRURITUS DERMATITIS PADA SANTRI PONDOK PESANTREN DI SURAKARTA
}

\author{
Sumanto, Maria Dewi Christiyowati \\ Kementerian Kesehatan Politeknik Kesehatan Surakarta Jurusan Akupunktur
}

\begin{abstract}
Dermatitis Atopic, Ig.E, Pruritus, Santri/ Students Ponpes Surakarta. The purpose of this study to determine the influencing of acupuncture therapy with poin $\mathrm{Bl}$ 13, Li 11, SP 10, ST 36 and HT 7 to improve Immunoglobin E (Ig.E) and to reduce pruritus scale for Santri with dermatitis in Pondok pesantren of Surakarta. Quasi experiment with one group pre test-post test design. The focus of research is the use of acupuncture to improve Ig.E and to reduce pruritus scale in Dermatitis Atopic. Acupuncture therapy acupuncture performed by trained therapists who have a permit or license from the competent authority official. Data were collected by interview/ anamnesis, observation and fill out a questionnaire after getting acupuncture therapy. Data analysis will use the t-test and ANOVA One-way to justify the data pre and post acupuncture treatment, then processed with SPSS 16.0 series. Acupuncture is effective in improving Ig.E and reducing pruritus intensity for santri/student in Pondok Pesantren Al Kahfi of Surakarta
\end{abstract}

Keywords: Dermatitis Atopic, Ig.E, Pruritus, Santri/Students Ponpes Surakarta

Abstrak: Dermatitis Atopik, Pruritus, Terapi Akupunktur. Tujuan penelitian ini untuk mengetahui Pengaruh terapi akupunktur pada titik Bl 13, Li 11, ST 36, SP 10 dan HT 7 terhadap Perbaikian Ig. E Pasien Pruritus Dermatitis pada Santri Pondok Pesantren di Surakarta. Quasi eksperimental dengan rancangan penelitian one Grous pretest - post test design.Fokus penelitian adalah Penggunaan terapi akupunktur untuk memperbaiki Ig,E, Pruritus (rasa gatal kulit). Terapi akupunktur dilakukan oleh tenaga kesehatan Akupunktur terapis yang memiliki ijin atau lisensi resmi dari badan yang berwenang. Pengambilan data dilakukan dengan wawancara/anamnesa dan observasi serta mengisi kuesioner setelah mendapatkan terapi akupunktur. Analisa data akan menggunakan ttest dan ANOVA ONEWAY untuk justifikasi data pre dan pos terapi akupunktur, kemudian diolah dengan Program SPSS seri 16,0. Akupunktur efektif memperbaiki Ig,E dan keluhan pruritus (rasa gatal kulit) santri Ponpes di Surkarta

Kata Kunci: Dermatitis Atopik, Pruritus, Terapi Akupunktur.

\section{PENDAHULUAN}

Terapi medis terhadap dermatitis/ eczem atopik membutuhkan pendekatan sistematis dan multifaktorial. Pendekatan tsb mengombinasi terapi hidrasi kulit, infeksi, dan stres emosional yang bersifat individual, namun juga ditekankan untuk mengatasi kekambuhan, perawatan kulit mandiri yang benar dan menghindari penyebab melalui edukasi personal higiene. Agen topical misalnya: kortikosteroid, antihistamin, antibiotic, 
pelembab dan cairan $\mathrm{NaCl} \quad 0,9 \%$ digunakan untuk terapi penyakit yang terlokalisasi dan ringan, sedangkan fototerapi dan agen sistemik digunakan untuk yang lebih luas dan berat. Terapi kortikosteroid untuk dermatitis atopik bersifat efektif, relatif cepat, ditoleransi dengan baik, mudah digunakan, dan harganya terjangkau masyarakat. Efek samping yang dapat terjadi pada dermatitis atopic usia anak walaupun jarang adalah terhambatnya pertumbuhan oleh supresi adrenal karena absorbsi sistemik, meskipun sampai saat ini belum ada bukti bahwa penggunaan kortikosteroid pada anak dapat mempengaruhi pertumbuhan tinggi badan.

Berdasar fenomena tsb di atas, perlu mencari solusi pasien dermatitis/ eczem atopic lain sebagai alternative dan atau komplementer terapi dermatitis/ eczema atopic; diantaranya adalah terapi akupunktur. Akupunktur secara tradisional merupakan upaya memperlancar hambatan energy (Qi) dan mengembalikan kelancaran sirkulasi energy melalui saluran meridian tubuh. Secara saintifikasi akupunktur bekerja dengan merangsang system penyembuhan alami tubuh.

Berdasar pada penelitian keilmuan telah ditemukan ada 3 (tiga) mekanisme kerja akupunktur yaitu: neurologi, biokimia dan biolistrik. Penelitian telah dilakukan sejak tahun 1980-an dijelaskan bahwa: akupunktur bekerja dengan merangsang pelepasan endorphin, keseimbangan cairan, elektrolit dan asam basa) kimia tubuh dan meningkatkan kelancaran peredaran darah serta perbaikan jaringan tubuh. Akupunktur mulai bekerja dari tempat penusukan jarum (lesi mikro) meneruskan signal saraf ke otak yang mengatur persepsi nyeri dan meningkatkan kinerja system saraf autonom untuk mengatur fungsi autonomi seperti kerja jantung, respirasi dan digesti. Akupunktur dapat meningkatkan aliran darah, karena tubuh memerlukan kesembuhan cidera dengan kecukupan darah, oksigen, nutrisi, zat immunitas, hormone, analgetik (pereda sakit) dan antiinflamasi. Perbaikan sirkulasi darah adalah penting untuk meningkatkan dan memelihara kesehatan tubuh. Efek terhadap neurotransmitter yaitu: stabilitas kadar Seratonin and noradrenaline baik di saraf pusat dan perifer selama terapi akupunktur dapat melancarkan pernafasan, menenangkan kecemasan dan relaksasi tubuh serta mempermudah tidur.

Berdasar uraian tersebut diatas, kami akan meneliti dengan judul pengaruh akupunktur terhadap perbaikan rasa gatal pruritus pasien dermatitis-eczema atopic pada Santri Pondok Pesentren Alkahfi Kota Surakarta.

\section{METODE PENELITIAN}

Berdasar tujuan penelitian ini, maka metoda penelitian dengan judul Pengaruh Akupunktur terhadap dermatitis atopik dengan gatal Santri Ponpes Alkahfi di Kota Surakarta adalah Quasi Eksperimental dengan kelompok kontrol.

Variabel penelitian ini meluputi: Variabel bebas yaitu Tindakan Akupunktur Titik Li11, ST36, HT7, dan SP9 dan Variabel terikat yaitu Perbaikan rasa gatal pada pasien dermatitis atopic Santri Ponpes Alkahfi di Kota Surakarta

Adapun jenis quasi eksperimen penelitian ini adalah pre-test dan post-test control group design, yaitu mengelompokkan sampel penelitian ke dalam kelompok perlakukan dan kelompok kontrol, kemudian melakukan tes sbelum perlakukan dan setelah 
perlakukan, tetapi penetapn sampelnya tanpa menggunakan random.

\begin{tabular}{|llll|}
\hline Non R & O-pre & $X$ & O-Post \\
Non R & O-pre & $=$ & O-post \\
& & & \\
\hline
\end{tabular}

\begin{tabular}{|l|l|l|}
\hline \multicolumn{2}{|c|}{ Kerangka Konsep } \\
VERIABEL \\
Li11, ST36, \\
HT7, dan SP10
\end{tabular}

Penelitian ini akan dilaksanakan selama 6 bulan pada bulan Oktober sampai dengan April 2016. Penelitian ini akan dilakjukan di ponpes Alkahfi Surakarta untuk kelompok usia remaja (12-15 tahun). Teknik pengambilan sampel secara non random, yaitu sampling purposif atau sampel non probabilitas.

Instrumen untuk mengidentifikasi karakteristik responden (usia, jenis kelamin dan tempat tinggal) menggunakan angket. Untuk mengidentifikasi kadar IG Esecara laboratorium klinik dan rasa gatal pruritus menggunakan instrument assessment terhadap derajat pruritus yaitu VAS (Visual Analoque Scale) terdiri 10 point visual analog scale (VAS) dan derajat gatalnya antara ringan (1-3), sedang (4-7) dan berat (8-10) (Adam Reich et.all: 2012). Pemeriksaan analisis darah (substanti allegen, mediator kimia, immunologi, serum elektrolit).

Data akan dianalisis menggunakan Uji-t dan ANOVA untuk mengetahui perbedaan dua kelompok perlakuan dan uji korelasi untuk mengetahui seberapa jauh perbedaan pada sampel dengan analisis regresi. Jika probabilitas $>0,05$ (atau 0,01) maka Ho diterima dan Jika probabilitas < 0,05 (atau 0,01) maka Ho ditolak $(0,05$ atau 0,01 adalah tergantung pilihan kita).

Uji Validitas adalah pengukuran keabsahan instrumen untuk digunakan menukur data dan nilai koefisien validitas penelitian ini berkisar $0.40-0.5$. Uji Realibilitas adalah pengukuran tingkat kepercayaan terhadap kebenaran alat untuk mengumpulkan data. Skala releabilitas instrumen dianggap cukup dipercaya jika nilainya berkisar 0.900 .

\section{HASIL PENELITIAN}

\section{Tabel 1}

Nilai Pre Dan Pos Terapi Akupunktur

Terhadap Ig.E Dan Gatal Kulit Sampel Berpasangan

\begin{tabular}{|c|c|c|c|c|c|c|}
\hline \multirow[t]{2}{*}{ Berpasangan } & \multirow[b]{2}{*}{ Mean } & \multirow[b]{2}{*}{$\begin{array}{c}\text { Std } \\
\text { Deviasi }\end{array}$} & \multicolumn{3}{|c|}{$\begin{array}{l}\text { Paired differences } \\
95 \% \text { Confidence } \\
\text { Interval of Difference }\end{array}$} & \multirow[t]{2}{*}{$\mathrm{t}$} \\
\hline & & & $\begin{array}{l}\text { Std. } \\
\text { Error } \\
\text { Mean }\end{array}$ & Lower & Upper & \\
\hline $\begin{array}{l}\text { Pair 1. Pre Ig.E } \\
\text { thd Post Ig.E }\end{array}$ & 43.5133 & 26.1368 & 6.7485 & 29.0393 & 57.987 & 6.448 \\
\hline $\begin{array}{l}\text { Pair 2. Pre } \\
\text { Gatal kulit thd } \\
\text { Post Gatal kulit }\end{array}$ & .933 & .458 & .118 & .680 & 1.187 & 7.897 \\
\hline
\end{tabular}

Tabel 1 di atas menunjukkan

adanya perbedaan Immunoglobulin $E$ (Ig.E) sebelum terapi akupunktur dengan Immunoglobulin E (Ig.E) sesudah terapi akupunktur; dan menunjukkan perbedaan nilai gatal kulit sebelum terapi akupunktur dan nilai gatal kulit sesudah terapi akupunktur. Berdasar nilai table uji t dan $\mathrm{F}$ pada $\mathrm{p}<0.005$ jumlah sampel 15 adalah 0.066162 . 
Table 2

Perbedaan Pre dan Pos Terapi Akupunktur Ig.E dan Rasa Gatal Kulit

\begin{tabular}{|c|c|c|c|c|c|}
\hline o & Variabel & Mean & $\begin{array}{l}\text { Stand. } \\
\text { dev }\end{array}$ & $\begin{array}{l}\text { Nilai } \\
\text { t-tes }\end{array}$ & $\begin{array}{l}\text { Sig. } \\
\text { 2tails }\end{array}$ \\
\hline & $\begin{array}{l}\text { Ig.E } \\
\text { sebelum } \\
\text { terapi } \\
\text { akupunktur } \\
\text { thd Ig. E } \\
\text { setelah } \\
\text { terapi } \\
\text { akupunktur }\end{array}$ & 285.507 & 206.9880 & .994 & .000 \\
\hline & $\begin{array}{l}\text { Rasa gatal } \\
\text { kulit } \\
\text { sebelum } \\
\text { terapi } \\
\text { akupunktur } \\
\text { thd rasa } \\
\text { gatal kulit } \\
\text { setelah } \\
\text { terapi } \\
\text { akupunktur }\end{array}$ & 2.93 & .799 & .869 & .000 \\
\hline
\end{tabular}

Berdasar table 2 bahwa terapi akupunktur titik Qu Chi (Li 11), Xuehai (Sp 10), Zusanli (St 36) dan Shen Men (Ht 7) menggambarkan adanya pengaruh terhadap penurunan konsentrasi Immunoglobulin E (Ig.E) dan intensitas skore rasa gatal kulit pada Santri yang merasa gatal Kulit secara signifikan.

Table 3

Tes Homogenitas Varian Nilai Ig.E Post Terapi Akupunktur

\begin{tabular}{|c|c|c|c|}
\hline $\begin{array}{l}\text { Levene } \\
\text { Statistic }\end{array}$ & df 1 & df 2 & Sig. \\
\hline 13.668 & 2 & 12 & .001 \\
\hline
\end{tabular}

menunjukkan bahwa variable penelitian ini homogen (sig. 0.001)

Table 4

Hasil Uji ANOVA

\begin{tabular}{cccccc}
\hline & $\begin{array}{c}\text { Sum of } \\
\text { squares }\end{array}$ & df & $\begin{array}{c}\text { mean } \\
\text { Squares }\end{array}$ & F & Sig. \\
\cline { 2 - 6 } Betwee & 317325.421 & 2 & 158662.71 & 9.372 & .00 \\
n group & & & 0 & & 4 \\
$\begin{array}{c}\text { With in } \\
\text { group } \\
\text { Total }\end{array}$ & 203155.608 & 12 & 16929.634 & & \\
\hline
\end{tabular}

Berdasar table 4 di atas maka terapi akupunktur dapat memperbaiki Immunoglobulin E (Ig.E) pada pasien pruritus dermatitis pada santri ponpes di Surakarta.

\section{PEMBAHASAN}

Pada bab ini peneliti akan menjelaskan dan mendiskusikan hasil penelitian ini dengan temuan dari penelitian sebelumnya berikut landasan teori pendukung dan teori kontra hasil penelitian ini.

Pembahasan hasil penelitian diawali dari interpretasi data nyeri perut bagian bawah pada wanita usia $18-21$ tahun (remaja akhir (pubertas)) dengan dismenore. Kemudian pengaruh terapi akupunktur titik Guanyuan (Ren 4), Guilai (ST 29) dan Sanyinjiao (Sp 6) terhadap penurunan intensitas nyeri haid dan durasi nyeri haid dan implikasi hasil penelitian pada pratik akupunktur gangguan siklus menstruasi sistem reproduksi wanita remaja.

Hasil penelitian ini akan diinterpretasikan dan didiskusikan berdarakan teori terkait dengan hasil penelitian sebelumnya. Hasil penelitian ini akan difokuskan pada pencapaian tujuan penelitian yaitu Efektifitas Akupunktur titik Guanyuan (Ren 4), Guilai (ST 29) dan Sanyinjiao ( $S p$ 6) terhadap penurunan intensitas nyeri haid dan durasi nyeri haid pada mahasiswi Politeknik Kesehatan Kemenkes Surakarta tahun 2013. Adapun hasil penelitian ini sebagai berikut:

Efektifitas Akupunktur titik Guanyuan (Ren 4), Guilai (ST 29) dan Sanyinjiao ( $\mathrm{Sp} \mathrm{6)}$ terhadap dismenore (penurunan intensitas nyeri haid dan durasi nyeri haid) pada mahasiswi Poltekkes Surakarta. 
Hasil penelitian ini ditemukan bahwa akupunktur titik Sanyinjiao (Sp 6) efektif menurunkan intensitas nyeri haid dan durasi nyeri haid pada wanita remaja dengan dismenore. Temuan ini juga pernah dilaporkan oleh Shahla Gharloghi (2010) bahwa intensitas nyeri haid wanita dismenore dapat dikurangi dengan akupresure titik Sanyinjiao secara empiris dapat mengurangi intensitas nyeri haid pada waita dengan dismenore primer $(\mathrm{p}<0,001$. Juga didukung oleh penemuan Chen HM, Chen CH (2004) bahwa dismenore dapat dikurangi dengan akupresure titik Sanyinjiao (SP 6) sebesar 94\%. Tuti Sukini, dkk juga menjwlaskan bahwa terapi akupresure dapat mengurangi nyeri haid wanita dismenore sebesar p<0.000 (Tuti Sukini, dkk 2012). Juga didukung oleh temuan Cho $\mathrm{SH}$, Hwang EW, (2010) bahwa akupresur dapat mengurangi nyeri haid pada wanita dengan dismenore primer.

Titik Sanyinjiao (SP 6) berada pada meridian limpa kaki, yaitu poksimal prominens maleolus medialis di sisi tepi posterior tulang tibialis. Titik sanyinjiao ini merupakan tempat pertemuan tiga Yin yaitu meridian limpa, hati dan ginjal (Saputra, 2005). Akupunktur meyakini bahwa titik Sanyinjiao bekerja menguatkan limpa dan lambung terkait dengan produksi energi (qi) dan darah, menghilangkan kelembaban, mengharmonisir kerja hati berikut menguatkan ginjal dapat berdampak pada pengaturan menstruasi dan menginduksi persalinan. Kemampuan mengharmonisir jiao bawah berdampak pada pengaturan kemih dan genetalia. Juga menenangkan mental-spirit, memperlancar peredaran darah pada tiga meridian Yin serta mengurangi rasa nyeri (Jeffrey (Ji Fei) Wang DOM, \& CH Wang, 2009).
Menurut Saputro K, (2005) bahwa pendekatan biomolekuler dapat menjelaskan kinerja akupunktur terhadap respons fisiologis tubuh. Titik akupunktur dapat menimbulkan rangsang primer pada sel aktif yang teluka oleh akupunktur memicu biomolekuler messenger. Titik akupunktur berada pada jalur meridian secara spesifik memiliki aliran elektron dan materi konduktif dapat menimbulkan interseluler signaling. Organ yang dilukai akupunktur menimbulkan efek spesifik dan menimbulkan morfofungsional sehingga menimbulkan stimulasi dan supresi, misalnya titik Sanyinjiao (Sp 6), titik Guanyuan (Ren 4) dan Gui lai (St 29) secara fisiologis dapat menormalkan hipotalamis pituitari ovarii (HPO) aksis melalui pelepasan hormon peptida (opioida) termasuk beta endorfin pada sistem saraf pusat dan perifer. Ketidak normalan sistem pituitari dapat menghambat produksi hormon $\mathrm{GnRH}$ pengatur siklus mentruasi dan fertilitas (E.A. Dugan, 2008).

Dismenore adalah nyeri haid menjelang atau selama haid, sebabkan oleh kejang otot uterus disebabkan oleh peningkatan hormon Prostaglandin dan menimbulkan otot polos (otot uterus) berkontraksi berlebih mengakibatkan aliran darah uterus menurun disertai penurunan oksigen otot uterus dan dapat memicu nyeri. Nyeri ini terasa di perut bagian bawah dan atau di daerah bujur sangkar Michaelis. Nyeri dapat terasa sebelum dan sesudah haid. Dapat bersifat kolik atau terus menerus sampai wanita tersebut tidak dapat bekerja dan harus tidur. Nyeri bersamaan dengan rasa mual, sakit kepala, perasaan mau pingsan, lekas marah.

Penyebab dari nyeri haid ini belum di temukan secara pasti meski telah 
banyak penelitian berusaha mencari penyebabnya. Adapun penyebab dysmenorrhea primer tersebut dihubungkan dengan faktor psikis dengan status emosi labil dan ambang nyeri rendah, dan faktor endokrin yaitu dihubungankan dengan kontraksi usus yang tidak baik. Hal ini sangat erat kaitannya dengan pengaruh hormonal, dimana peningkatan produksi prostaglandin akan menyebabkan kontraksi uterus yang tidak terkoordinasi sehingga menimbulkan nyeri.

Efek akupunktur titik Sanyinjiao (Sp 6), Guanyuan (Ren 4) dan Guilai (St 29) dapat megurangi lama sakit nyeri haid mahasiswi Poltekkes surakarta dengan dismenore.

Pada umumnya mahasiswi poltekkes Surakarta dengan dismenore primer merasa nyeri haid saat menjelang menstruasi sampai dengan beberapa hari saat menstruasi yaitu paling sedikit tiga sampai lima hari (satu hari menjelang haid dan dua sampai lima hari saat haid).

Titik akupunktur dapat memperpendek lama nyeri haid pada mahasiswi poltekkes kemenkes surakarta diantara sebelum tindakan akupunktur dan setelah tindakan akupunktur $(\mathrm{p}<0.001)$.

Wong CL et al (2010) menjelaskan bahwa akupresure titik Sanyinjiao (SP 6) pada wanita dismenore primer dapat mengurangi rasa nyeri haid, dan distress psikis pada saat awal menstruasi setelah dilakukan tindakan selama tiga bulan teratur. Temuan ini juga didukung oleh Chen HM, Chen CH, (2010) bahwa setelah dilakukan tindakan akupresur pada titik Sanyinjiao (Sp 6). Hegu (Li 4) secara bersama selama 6 bulan wanita remaja dengan dismenore dapat merasa nyaman sehari sebelum menstruasi sampai dengan menstruasi berakhir.

\section{KESIMPULAN DAN SARAN}

1. Berdasarkan analisis data tersebut di atas, maka titik akupunkturyaitu titik Li11, ST36, HT7, dan SP9 dapat memperbaiki Immunoglobulin E (Ig.E) pada pasien pruritus dermatitis pada santri ponpes Al Kahfi di Surakarta dengan nilai uji $\mathrm{F} 9.372$ dan signifikan 0.004 dengan SPSS seri 17.0. Terapi akupunktur titik B1 13 Feishu, Qu Chi (Li 11), Xuehai (Sp 10), Zusanli (St 36) dan Shen Men (Ht 7) menggambarkan adanya pengaruh pada penurunan Immunoglobulin E (Ig.E) dan intensitas rasa gatal kulit pada Santri yang merasa gatal kulit di Ponpes Al Kahfi Surakarta.

2. Terapi akupunktur menjadi pilihan terapi bagi seseorang yang mengalami hipersensitif tipe 1 terkait peningkatan Ig.E dan kerusakan sel mast.

3. Para Santri Ponpes di Surakarta yang mengalami radang kulit dan gatal kulit sebaiknya menggunakan terapi akupunktur untuk mengatasi rasa gatal dan radang kulit secara berkesinambungan.

4. Penelitian ini tidak menggunakan kelompok kontrol sehingga perlu dikembangkan design kelompok kontrol.

\section{DAFTAR RUJUKAN}

Leung DYM, et al. (2008). Atopic dermatitis (atopic eczema). In $\mathrm{K}$ Wolff et al., eds., Fitzpatrick's Dermatology in General Medicine, 7th ed., vol. 1, pp. 146-158. New York: McGraw-Hill.

Boguniewicz M, Leung DYM (2009). Atopic dermatitis. In $\mathrm{N}$ Franklin Addison Jr et al., eds., Middleton's Allergy Principles and Practice, 
7th ed., vol. 2, pp. 1083-1103. Philadelphia: Mosby Elsevier.

Berger TG (2012). Dermatologic disorders. In SJ McPhee, MA Papadakis, eds., 2012 Current Medical Diagnosis and Treatment, 51st ed., pp. 93-163. New York: McGraw-Hill.

Bieber T (2008). Mechanisms of disease: Atopic dermatitis. New England Journal of Medicine, 358(14): 1483-1494.

Christine e. Correale, colleen walker,., lydia murphy, and timothy j. Craig, Atopic Dermatitis: A Review of Diagnosis and Treatment Pennsylvania State University College of Medicine, Hershey, Pennsylvania. Am Fam Physician. 1999 Sep 15;60(4):1191 $-1198$.

Danisa Diandra Safarina 1, Muslimin, 2014 Karakteristik penderita dermatitis atopik di poliklinik rsup dr. Kariadi semarang. Jurnal medika muda. FK. UNDIP Semarang

Habif TP (2010). Atopic dermatitis. In Clinical Dermatology, A Color Guide to Diagnosis and Therapy, 5th ed., pp. 154-180. Edinburgh: Mosby Elsevier.

Habif TP, et al. (2011). Atopic dermatitis. In Skin Disease: Diagnosis and Treatment, 3rd ed., pp. 71-76. Edinburgh: Saunders.

Krakowski AC, et al. (2008). Management of atopic dermatitis in the pediatric population. Pediatrics, 122(4): 812-824.

Natalia*, Sri Linuwih Menaldi**, Triana Agustin** Perkembangan Terkini pada Terapi Dermatitis
Siti Aisah Boediardja, 1997 dari kepustakaan : William $\mathrm{HC}$ et al. Working Party Report. The UK Working Party's Diagnostic Criteria for Atopic Dermatitis II. Observer variation of clinical diagnosis and sign of atopic dermatitis, British J Dermatol. 1994, 131;397-405.

Stevens SR, et al. (2008). Eczematous disorders, atopic dermatitis, and ichthyoses. In EG Nabel, ed., ACP Medicine, section 2, chap. 4. Hamilton, ON: BC Decker.

U.S. Food and Drug Administration (2006). FDA approves updated labeling with boxed warning and medication guide for two eczema drugs, Elidel and Protopic. FDA News. Available online: 